\title{
Protective Effects of In Vitro Gastrointestinal Digests of Abalone (Haliotis discus hannai) Intestines against Oxidative Stress in RAW264.7 Macrophage Cells
}

\author{
Phuong Hong Nguyen ${ }^{1}$, Sun-Ae Kim ${ }^{1}$, Il-Whan Choi ${ }^{2}$ and Won-Kyo Jung ${ }^{1 *}$ \\ ${ }^{1}$ Department of Marine Life Science, and Marine Life Research Center, College of Natural Sciences, \\ Chosun University, Gwangju 501-759, Korea \\ ${ }^{2}$ Department of Microbiology, and Bio-Marker Research Center for Personalized Therapy, \\ College of Medicine, Inje University, Busan 614-735, Korea
}

\begin{abstract}
Abalone (Haliotis discus hannai), mostly distributed and maricultured in southwestern coastal areas of South Korea, is recognized as an economically important species in the fishery industry. Abalone intestines are one of the by-products of abalone processing. To investigate abalone intestines as bioactive substances, abalone intestine gastrointestinal digests (AIGIDs) of various molecular weights (MWs) were prepared using in vitro gastrointestinal digestion and an ultrafiltration system, and tested for inhibitory effects against reactive oxygen species (ROS) and oxidative stress in macrophage cells treated with hydrogen peroxide $\left(\mathrm{H}_{2} \mathrm{O}_{2}\right)$. In our results, among AIGIDs, AIGID-III (MW=5-10 kDa) showed potent inhibitory activities for lipid peroxidation and free radicals. Additionally, the results clearly indicated that AIGID-III treatment could prevent cytotoxic damage of macrophages by $\mathrm{H}_{2} \mathrm{O}_{2}$ induced oxidative stress due to its potent scavenging ability against cellular ROS. These results suggest that AIGIDs may have protective and therapeutic potential for oxidative stress syndromes and immune diseases through ROS inhibition in macrophage cells.
\end{abstract}

Key words: Abalone, Haliotis discus hannai, Intestine, In vitro gastrointestinal digestion, Antioxidant, ROS

\section{Introduction}

Oxidative stress by reactive oxygen species (ROS) is responsible for injuries to all the important cellular components and tissues. High levels of ROS, both free radicals and non-free radicals, have been implicated as the cause of many diseases such as cancer, diabetes, aging, and inflammatory diseases (Rackov et al., 2007). Free radicals consist of the peroxyl (ROO·), nitric oxide (NO·), hydroxyl $(\cdot \mathrm{OH})$, and superoxide radicals $\left(\mathrm{O}_{2}{ }^{-}\right)$. Non-free radicals consist of singlet oxygen $\left({ }^{1} \mathrm{O}_{2}\right)$ and hydrogen peroxide $\left(\mathrm{H}_{2} \mathrm{O}_{2}\right)$ (Lee et al., 2010). ROS produced during normal physiological events and by external conditions such as smoking, stress, and disease are removed by antioxidant-defensive mechanisms. These defensive mechanisms include anti-oxidative enzymes, such as superoxide dismutase, catalase, and glutathione peroxidase, and small molecules, such as

*Corresponding author: wkjung@chosun.ac.kr glutathione, vitamin $\mathrm{C}$, and vitamin $\mathrm{E}$ (Halliwell and Gutteridge, 1990). The endogenous and exogenous antioxidants play a crucial role controlling free radicals to reduce cell and tissue damage (Aruoma, 1994; Halliwell, 1994).

Many natural antioxidants have been identified as free radical or active oxygen scavengers (Duh, 1998; Pan et al., 2007). Recently, research interests have considerably increased in finding natural antioxidants for use in foods or medicinal materials to replace synthetic antioxidants, which have been restricted due to side effects such as carcinogenicity. These natural antioxidants can effectively protect the human body from free radicals and retard the progress of many chronic diseases as well as oxidative rancidity in foods or medicinal materials without any side effects (Kim et al., 2006; Jung et al., 2007; Qian et al., 2008).

Marine organism-derived proteins and peptides possess various bioactive compounds with many nutraceutical and pharmaceutical activities that are related to physiological functions such as anti- 
coagulation (Jo et al., 2008), antimicrobial effects (Liu et al., 2008), antihypertension (Byun and Kim, 2001), and cardiovascular disease (Mendis et al., 2005; Kim et al., 2006; Erdmann et al., 2008). Depending on the amino acid composition as well as molecular size, bioactive peptides can be involved in diverse biological functions (Elias et al., 2008). During gastrointestinal digestion, proteolytic digestion can generate absorbable and bioactive peptides in the stomach and small intestinal tracts (Roberts et al., 1999; Vermeirssen et al., 2004). With the advantage that the formed peptides will resist physiological digestion after oral intake, the digestion by gastrointestinal proteases can be useful as a production process for antioxidant peptides. Some recent studies have reported that in vitro gastrointestinal digests of marine organisms possessed biological activities as potent as that of other natural antioxidants (Jung et al., 2007; Qian et al., 2008).

Abalone is a marine gastropod, and one of the most commercially important fishery resources in Asian cultures (Zhu et al., 2008). To meet the current increasing demand of the Asian, American, Australian, and EU market, abalone culture is expanding in landand sea-based systems worldwide and is expected to produce 7,580 metric tons of abalone in 2009 in South Korea (The Korea Maritime Institute, KMI). Among abalone species cultured, Haliotis discus hannai is the most commercially important species in South Korea. Although H. discus hannai is an important species among fishery resources, their biological activities have been rarely studied (Ekanayake et al., 2008; Wan et al., 2008; Sun et al., 2010).

In the present study, the objective of our research was to evaluate the antioxidant potential of $H$. discus hannai abalone intestine gastrointestinal digests (AIGIDs) and elucidate the protective effects against oxidative stress in macrophage cells.

\section{Materials and Methods}

\section{Materials}

Live adult abalone (H. discus hannai) were collected from Wando Island, Wando-gun, South Korea. Intestinal organs (guts) were separated from the washed abalone and lyophilized. RAW264.7 macrophage cells were obtained from the American Type Culture Collection (ATCC, Manassas, VA, USA). Dulbecco's modified Eagle's medium (DMEM), trypsin-EDTA, penicillin/streptomycin/ amphotericin $(10,000 \mathrm{U} / \mathrm{mL}, 10,000 \mu \mathrm{g} / \mathrm{mL}$, and $2,500 \mu \mathrm{g} / \mathrm{mL}$, respectively), and fetal bovine serum
(FBS) were obtained from Gibco-BRL Life Technologies (Grand Island, NY, USA). MTT (3(4,5-dimethyl-2-yl)-2,5-diphenyltetrazolium bromide) reagent, 5,5-dimethyl-1-pyrroline-N-oxide (DMPO), $\alpha$-(4-pyridyl-1-oxide)-N-tertbutylnitrone (4-POBN), 2,2'-azobis(2-amidinopropane) dihydrochloride (AAPH), and Folin-Ciocalteu reagent were purchased from Sigma Chemical Co. (St. Louis, MO, USA). $2^{\prime}, 7^{\prime}$-Dichlorofluorescin diacetate (DCFH-DA) was purchased from Molecular Probes (Eugene, OR, USA). Other chemicals and reagents used were of analytical grade.

\section{In vitro gastrointestinal digestion}

The digestion process used the method described by Kapsokefalou and Miller (1991). One hundred milliliters of $4 \%(\mathrm{w} / \mathrm{v})$ abalone intestine solution was brought to $\mathrm{pH} 2.2$ in gastric digestion (phase I) using $1 \mathrm{M} \mathrm{HCl}$ and $10 \mathrm{M} \mathrm{NaOH}$ under vigorous mixing. Pepsin (EC 3.4.23.1., 400-800 U/mg protein; Sigma Chemical Co.) was added at an enzyme to substrate ratio of $1 / 100(\mathrm{w} / \mathrm{w})$, then incubated at $37^{\circ} \mathrm{C}$ on a shaker. After $2 \mathrm{~h}$, the $\mathrm{pH}$ was set to 6.5 to obtain the conditions of small intestinal digestion (phase II). Similarly, trypsin (EC 3.4.21.4., $30 \mathrm{U} / \mathrm{mg}$ protein; Wako Pure Chemical Ltd., Osaka, Japan) and $\alpha$ chymotrypsin (EC 3.4.21.1., $60 \mathrm{U} / \mathrm{mg}$ protein; ICN Biomedical Inc., Aurora, OH, USA) were both supplemented at an enzyme to substrate ratio of $1 / 100$ $(\mathrm{w} / \mathrm{w})$. The solution was further incubated at $37^{\circ} \mathrm{C}$ for $2.5 \mathrm{~h}$. When samples were taken at the beginning and end of digestion, the $\mathrm{pH}$ was adjusted to 6.5. Samples were centrifuged at $10,000 \times g$ for $15 \mathrm{~min}$ at $4^{\circ} \mathrm{C}$, and the supernatant was lyophilized to obtain powdered AIGIDs.

\section{Preparation of AIGIDs with various MWs using a UF membrane bioreactor system}

AIGIDs were fractionated through ultrafiltration (UF) membranes with a range of molecular weight cutoffs (MWCOs) of 100, 10, 5 and $1 \mathrm{kDa}$, respectively. Fractions were designed as follows: AIGID-I with MW $>100 \mathrm{kDa}$, AIGID-II with MW of 100-10 kDa, AIGID-III with MW of 10-5 kDa, and AIGID-IV with MW of 5-1 kDa. AIGIDs I-IV were lyophilized and stored at $-20^{\circ} \mathrm{C}$.

\section{Measurement of anti-oxidative activity in a linoleic acid model system}

Inhibition of lipid peroxidation by AIGIDs was measured in a linoleic acid oxidation system according to the methods of Osawa and Namiki (1985). Briefly, to make a $1 \%$ sample solution in an emulsion of linoleic acid and ethanol, $1.3 \mathrm{mg}$ of sample was 
dissolved in $10 \mathrm{~mL}$ of $50 \mathrm{mM}$ phosphate buffer $(\mathrm{pH}$ 7.0) and added to a solution of $0.13 \mathrm{~mL}$ linoleic acid and $10 \mathrm{~mL} 99.5 \%$ ethanol. Then the total volume of the emulsion was adjusted to $25 \mathrm{~mL}$ with distilled water. The emulsion was incubated in a conical flask with a screw cap at $40 \pm 1^{\circ} \mathrm{C}$ in darkness. The degree of oxidation was evaluated by measuring ferric thiocyanate values according to the method of Mitsuda et al. (1966). The emulsion $(100 \mu \mathrm{L})$ incubated in the linoleic acid model system was mixed with $4.7 \mathrm{~mL}$ of $75 \%$ ethanol, $0.1 \mathrm{~mL}$ of $30 \%$ ammonium thiocyanate, and $0.1 \mathrm{~mL}$ of $20 \mathrm{mM}$ ferrous chloride solution in $3.5 \% \mathrm{HCl}$. After $3 \mathrm{~min}$, the thiocyanate value was measured based on the absorbance at $500 \mathrm{~nm}$ following color development with $\mathrm{FeCl}_{2}$ and thiocyanate at different intervals during the incubation period at $40 \pm 1^{\circ} \mathrm{C}$.

\section{Amino acid composition analysis}

For the determination of amino acid composition, the lyophilized AIGID-III (20 mg of powder) was hydrolyzed in $6 \mathrm{~N} \mathrm{HCl}$ containing $0.1 \%$ thioglycolic acid at $110^{\circ} \mathrm{C}$ for $24 \mathrm{~h}$ under vacuum. Amino acids derived with phenylisothiocyanate were identified and quantified using an automatic amino acid analyzer (Biochrom 20; Pharmacia Biotech, Uppsala, Sweden).

\section{Measurement of free radical scavenging activity by electron spin resonance (ESR) spectroscopy}

Diverse radicals were generated according to the following procedures, and spin adducts were recorded using a JES-FA electron spin resonance (ESR) spectrometer (JEOL Ltd., Tokyo, Japan). Radical scavenging ability was calculated with following equation in which $\mathrm{H}$ and $\mathrm{H}_{\mathrm{o}}$ were the relative peak height of the radical signals with and without sample, respectively.

$$
\text { Radical scavenging activity }=\left[\frac{1-\mathrm{H}}{\mathrm{H}_{0}}\right] \times 100
$$

\section{Scavenging effect on the DPPH radical}

DPPH radical scavenging activity was measured using the method described by Nanjo et al. (1995). A $30 \mu \mathrm{L}$ sample solution (or ethanol as a blank) was added to $30 \mu \mathrm{L}$ of DPPH $(60 \mu \mathrm{M})$ in ethanol. After mixing vigorously for $10 \mathrm{~s}$, the solution was then transferred to a $100 \mu \mathrm{L}$ quartz capillary tube, and the scavenging activity was measured using the ESR spectrometer. The spin adduct was measured on the ESR spectrometer exactly 2 min later. Experimental conditions were as follows: magnetic field, $336.5 \pm 5$ $\mathrm{mT}$; power, $5 \mathrm{~mW}$; modulation frequency, $9.41 \mathrm{GHz}$; amplitude, $1 \times 1000$; sweep time, $30 \mathrm{~s}$. DPPH radical scavenging ability was calculated with the previous equation in which $\mathrm{H}$ and $\mathrm{H}_{\mathrm{o}}$ were the relative peak height of the radical signals with and without sample, respectively.

\section{Hydroxyl radical scavenging activity}

Hydroxyl radicals were generated by the ironcatalyzed Fenton Haber-Weiss reaction, and the generated hydroxyl radicals were rapidly reacted with nitrone spin traps (DMPO) (Rosen and Rauckman, 1984). The resultant DMPO-OH adducts were detectable with an ESR spectrometer. The sample solution $(20 \mu \mathrm{L})$ was mixed with DMPO $(0.3 \mathrm{M}, 20$ $\mu \mathrm{L}), \mathrm{FeSO}_{4}(10 \mathrm{mM}, 20 \mu \mathrm{L})$, and $\mathrm{H}_{2} \mathrm{O}_{2}(10 \mathrm{mM}, 20$ $\mu \mathrm{L}$ ) in a phosphate buffer solution ( $\mathrm{pH} 7.4)$, and then transferred to a $100 \mu \mathrm{L}$ quartz capillary tube. After $2.5 \mathrm{~min}$, the ESR spectrum was recorded using an ESR spectrometer. The experimental conditions employed were as follows: magnetic field, $336.5 \pm 5$ $\mathrm{mT}$; power, $1 \mathrm{~mW}$; modulation frequency, $9.41 \mathrm{GHz}$; amplitude, $1 \times 200$; sweep time, $4 \mathrm{~min}$. Hydroxyl radical scavenging ability was calculated as the previous equation in which $\mathrm{H}$ and $\mathrm{H}_{\mathrm{o}}$ were the relative peak height of the radical signals with and without sample, respectively.

\section{Superoxide anion radical scavenging activity}

Superoxide anion radicals were generated by a UVirradiated riboflavin/EDTA system (Guo et al., 1999). The reaction mixture containing $0.3 \mathrm{mM}$ riboflavin, $1.6 \mathrm{mM}$ EDTA, $800 \mathrm{mM}$ DMPO, and sample was irradiated for $1 \mathrm{~min}$ under a UV lamp at $365 \mathrm{~nm}$. The reaction mixture was transferred to a $100 \mu \mathrm{L}$ ESR quartz capillary tube for measurement. The experimental conditions were as follows: magnetic field, $336.5 \pm 5 \mathrm{mT}$; power, $10 \mathrm{~mW}$; modulation frequency, $9.41 \mathrm{GHz}$; amplitude, $1 \times 1000$; sweep time, $1 \mathrm{~min}$. Superoxide radical scavenging ability was calculated as the previous equation in which $\mathrm{H}$ and $\mathrm{H}_{0}$ were the relative peak height of the radical signals with and without sample, respectively.

\section{Peroxyl radical scavenging activity}

Alkyl radicals were generated according to the method of Hiramoto et al. (1993). Briefly, $20 \mu \mathrm{L}$ of $40 \mathrm{mM}$ 2,20-azobis (2-amidinopropane) dihydrochloride (AAPH) was mixed with $20 \mu \mathrm{L}$ of phosphate buffered-saline (PBS), $20 \mu \mathrm{L}$ of $40 \mathrm{mM}$ a-(4-pyridyl1-oxide)-N-tert-butylnitrone (4-POBN), and $20 \mu \mathrm{L}$ of sample solution. The mixture was incubated at $37^{\circ} \mathrm{C}$ for $30 \mathrm{~min}$, and then transferred to a $100 \mu \mathrm{L}$ ESR quartz capillary tube for measurement. The experimental conditions were as follows: modulation fre- 
quency, $100 \mathrm{kHz}$; microwave power, $10 \mathrm{~mW}$; microwave frequency, $9441 \mathrm{MHz}$; magnetic field, $336.5 \pm 5$ $\mathrm{mT}$; and sweep time, $30 \mathrm{~s}$. Peroxyl radical scavenging ability was calculated as the previous equation in which $\mathrm{H}$ and $\mathrm{H}_{\mathrm{o}}$ were the relative peak height of the radical signals with and without sample, respectively.

\section{Cell culture and viability determination}

RAW264.7 macrophages were cultured in DMEM containing $10 \%$ FBS, $100 \mathrm{U} / \mathrm{mL}$ penicillin, and 100 $\mu \mathrm{g} / \mathrm{mL}$ streptomycin at $37^{\circ} \mathrm{C}$ in a $5 \% \mathrm{CO}_{2}$ humidified air environment. Cell viability was measured based on the formation of blue formazan metabolized from colorless MTT by mitochondrial dehydrogenases, which are active only in live cells. RAW264.7 macrophages were plated in 96-well plates at a density of $4 \times 10^{3}$ cells per well for $24 \mathrm{~h}$, and then washed. Cells incubated with various concentrations of samples were incubated in $0.5 \mathrm{mg} / \mathrm{mL}$ MTT solution. Three hours later, the supernatant was removed and the formation of formazan was measured at $540 \mathrm{~nm}$ using a microplate reader (PowerWave XS model; BioTek Instruments, Inc., Winooski, VT, USA).

\section{Measurement for cytotoxicity on $\mathrm{H}_{2} \mathrm{O}_{2}$-induced RAW264.7 cells}

Cells were treated with various concentrations of the AIGID-III and incubated for $10 \mathrm{~h}$. Cellular oxidation was accelerated by exposing cells to 200 $\mu \mathrm{M} \mathrm{H}_{2} \mathrm{O}_{2}$. After $6 \mathrm{~h}$, cell viability was measured using the MTT method. Data were expressed as the mean percentages of viable cells compared to the respective control culture.

\section{Cellular ROS determination by DCFH-DA}

Intracellular formation of ROS was assessed using oxidation sensitive dye, 2', 7'-dichlorofluorescin diacetate (DCFH-DA), as the substrate (Okimoto et al., 2000). RAW264.7 cells cultured in fluorescence microtiter 96-well plates were loaded with $20 \mu \mathrm{M}$ DCFH-DA in Hank's balanced salt solution (HBSS) and incubated for $20 \mathrm{~min}$ in darkness. Nonfluorescent DCFH-DA dye freely penetrates into cells and is hydrolyzed by intracellular esterases to $2^{\prime}, 7^{\prime}$ dichlorofluorescin (DCFH). Cells were then treated with different concentrations of test extracts and incubated for $1 \mathrm{~h}$. After washing the cells with PBS three times, $300 \mu \mathrm{M} \mathrm{H}_{2} \mathrm{O}_{2}$ dissolved in HBSS was added to the cells. The formation of DCF due to the oxidation of DCFH in the presence of various ROS was measured every $30 \mathrm{~min}$ at an excitation wavelength (Ex) of $485 \mathrm{~nm}$ and an emission wavelength
(Em) of $535 \mathrm{~nm}$ using the microplate reader. Dosedependent and time-dependent effects of AIDIG-III treatment groups were plotted and compared to the fluorescence intensity of the control and blank groups.

\section{Statistical analysis}

Data were expressed as the mean \pm standard error of the mean $(n=3)$. Student's $t$ test was used to determine the level of significance $(P<0.05)$.

\section{Results and Discussion}

\section{Preparation of AIGIDs and antioxidant activity in linoleic acid model systems}

To generate anti-oxidative digests from abalone intestine, an in vitro gastrointestinal (GI) digestion system was applied. The GI digestion consisted of hydrolysis processes that simulated physiological digestions: gastric digestion (phase 1) corresponded to a pepsin-hydrolysis, and intestine digestion (phase 2) corresponded to proteolysis by two enzymes (trypsin and $\alpha$-chymotrypsin). The results of the lipid peroxidation inhibitory assay using a linoleic acid model (Table 1), the anti-oxidative activity of gastrointestinal digests (phase 2; 88.2 $\pm 7.2 \%$ ) was significantly elevated after GI digestion of abalone intestines. The activity of gastric digests (phase 1) showed an inhibition value of $69.8 \pm 5.7 \%$. The results indicated that the constituent proteins or peptides of AIGIDs are the precursors of antioxidant peptides via the action of GI enzymes.

Table 1. Inhibitory effects of gastrointestinal digests of abalone intestine against lipid peroxidation

\begin{tabular}{lc}
\hline Digestion phase & $\begin{array}{c}\text { Inhibition of lipid } \\
\text { peroxidation (\%) }\end{array}$ \\
\hline Gastric digests (phase 1) & $69.8 \pm 7.7$ \\
Gastrointestinal digests (phase 2) & $88.2 \pm 7.2$ \\
\hline
\end{tabular}

AIGIDs with potent antioxidant activity in the linoleic acid model system were further separated into four MW groups: AIGID-I $(<100 \mathrm{kDa})$, AIGIDII (10-100 kDa), AIGID-III (5-10 kDa), and AIGIDIV (1-5 kDa) using a UF membrane system (MWCOs: 100, 10, 5, and $1 \mathrm{kDa}$ ). The direct free radical scavenging effects of AIGIDs (AIGID-I to IV) were investigated using an ESR spin-trapping technique. DPPH is a stable free radical and acceptor for an electron or hydrogen to become a stable diamagnetic molecule. Therefore, DPPH is often used as a substrate to evaluate antioxidant activity. An ESR spectrometer can visualize hydroxyl radicals generated by the Fenton reaction. The ESR signals 
become weak in the presence of $\cdot \mathrm{OH}$ scavengers, which compete with DMPO for $\mathrm{OH}$. Superoxide radicals were generated by UV irradiation of a riboflavin/EDTA solution. AAPH can decompose to form carbon-centered radicals that can react swiftly with $\mathrm{O}_{2}$ to yield peroxyl radicals to stimulate lipid peroxidation (Halliwell and Gutteridge, 1990). Table 2 shows the free radical scavenging activities of the four groups against different radical sources. The results showed that AIGID-III exhibited higher free radical scavenging activity than the other groups. At 1 $\mathrm{mg} / \mathrm{mL}$, AIGID-III exhibited considerable scavenging activity of $84.3 \%, 81.9 \%, 72.6 \%$, and $60.9 \%$ of DPPH, hydroxyl, superoxide, and peroxyl radicals, respectively. Additionally, AIGID-III exhibited ROS scavenging activity in dose-dependent manner (Fig. 1).

Table 2. Free radical scavenging activity of AIGIDs

\begin{tabular}{lllll}
\hline \multirow{2}{*}{$\begin{array}{l}\text { AIGIDs } \\
(1 \mathrm{mg} / \mathrm{mL})\end{array}$} & \multicolumn{4}{c}{ Radical scavenging activity (\%) } \\
\cline { 2 - 5 } & \multicolumn{1}{c}{ DPPH } & Hydroxyl & superoxide & peroxyl \\
\hline AIGID I & $86.2 \pm 1.5^{*}$ & $68.6 \pm 1.7$ & $70.8 \pm 1.6$ & $60.8 \pm 1.7^{*}$ \\
AIGID II & $75.3 \pm 1.2$ & $70.6 \pm 2.6$ & $69.4 \pm 2.0$ & $56.2 \pm 2.5$ \\
AIGID III & $84.3 \pm 0.8^{*}$ & $81.9 \pm 2.3^{*}$ & $72.6 \pm 3.0^{*}$ & $60.9 \pm 1.6^{*}$ \\
AIGID IV & $59.6 \pm 2.2$ & $48.2 \pm 1.8$ & $46.2 \pm 1.8$ & $30.6 \pm 1.9$
\end{tabular}

The asterisk $(*)$ indicated a significant difference among the tested groups $(P<0.05)$. Values are mean $\pm \mathrm{SD}(\mathrm{n}=3)$.

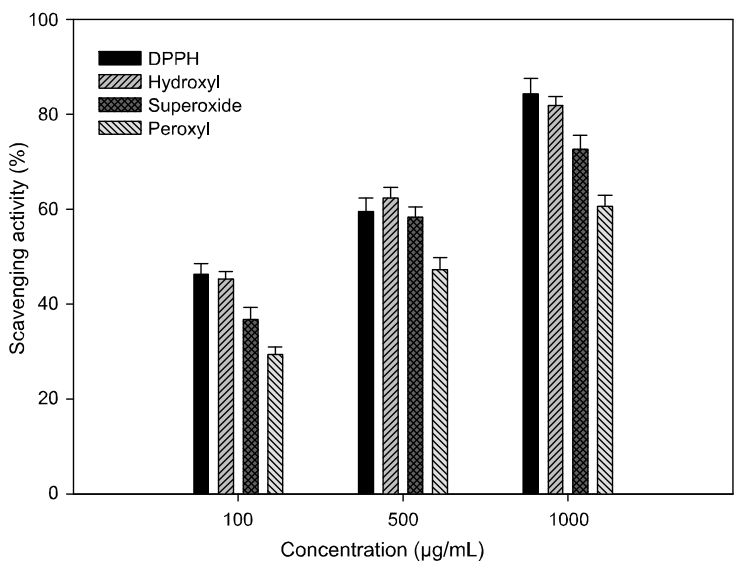

Fig. 1. Free radical scavenging activity in the presence of various concentrations of AIGID-III using ESR spectrometer.

As shown in Table 3, the amino acid composition of AIGID-III explains the antioxidant activity by its being composed of hydrophobic and hydrogendonating amino acids such as $\mathrm{Glu} / \mathrm{n}(355 \mathrm{mg} / \mathrm{g}$, w/w), Asp/n (89 mg/g, w/w), Gly (66.3 mg/g, w/w), Lys (54.7 mg/g, w/w), Leu (47 mg/g, w/w), Thr (43.1 $\mathrm{mg} / \mathrm{g}, \mathrm{w} / \mathrm{w})$, Ser $(44.7 \mathrm{mg} / \mathrm{g}, \mathrm{w} / \mathrm{w}), \operatorname{Arg}(41.6 \mathrm{mg} / \mathrm{g})$, and Ala $(40.8 \mathrm{mg} / \mathrm{g}, \mathrm{w} / \mathrm{w})$.
Table 3. Contents of compositional amino acids in AIGID-III (mg/g)

\begin{tabular}{lc}
\hline Amino acids & Intestine \\
\hline Asp/n & 89.4 \\
Thr & 43.1 \\
Ser & 44.7 \\
Glu/n & 355.9 \\
Gly & 66.3 \\
Ala & 40.8 \\
Cys & 14.6 \\
Val & 39.3 \\
Met & 16.9 \\
Ile & 26.2 \\
Leu & 47 \\
Tyr & 30.8 \\
Phe & 31.6 \\
Lys & 54.7 \\
Trp & 1.5 \\
His & 23.9 \\
Arg & 41.6 \\
Pro & 31.6 \\
\hline Total & 1,000 \\
\hline
\end{tabular}

Bioactive peptides usually contain less than 50 amino acid residues per molecule, and the lower molecular weight of these molecules can give a higher probability of crossing the intestinal barrier and exert biological effects (Roberts et al., 1999). Lipid peroxidation is thought to proceed via radicalmediated abstraction of hydrogen atoms from methylene carbons in polyunsaturated fatty acids. Since the hydrophobicity of antioxidants is important for accessibility to the hydrophobic targets (Chen et al., 1995), the presence of hydrophobic amino acids in the active peptides may have contributed to lipid peroxidation inhibitory activity by increasing the solubility of peptides in lipid and thereby facilitating better interaction with radical species. Additionally, the presence of the hydrophobic amino acid Leu in the AIGID-III could be important for antioxidant activity (Chen et al., 1995) because Leu is assumed to increase the interaction between peptides and fatty acids. Additionally, the presence of Asp seems to play a vital role irrespective of its position as observed in several anti-oxidative peptide sequences. The chemical activity of the hydroxyl radical is the strongest among ROS. It easily reacts with biomolecules, such as amino acids, proteins, and DNA (Cacciuttolo et al., 1993). Therefore, the removal of hydroxyl radicals is one of the most effective defenses of a living body against various diseases. As a whole, the potent antioxidant activity of AIGID-III could be attributable to the presence of specific amino acids and the distribution of molecular size. 
MTT assay and protective effects of AIGID-III against $\mathrm{H}_{2} \mathrm{O}_{2}$-induced cytotoxicity

Cytotoxic effects of AIGID-III were evaluated on mouse macrophages (RAW264.7). The results showed that AIGID-III had no cytotoxic effects on RAW264.7 cells at the tested concentrations (Fig. 2). Therefore, nontoxic concentrations of AIGID-III $(100-1,000 \mu \mathrm{g} / \mathrm{mL})$ were used for this experiment.

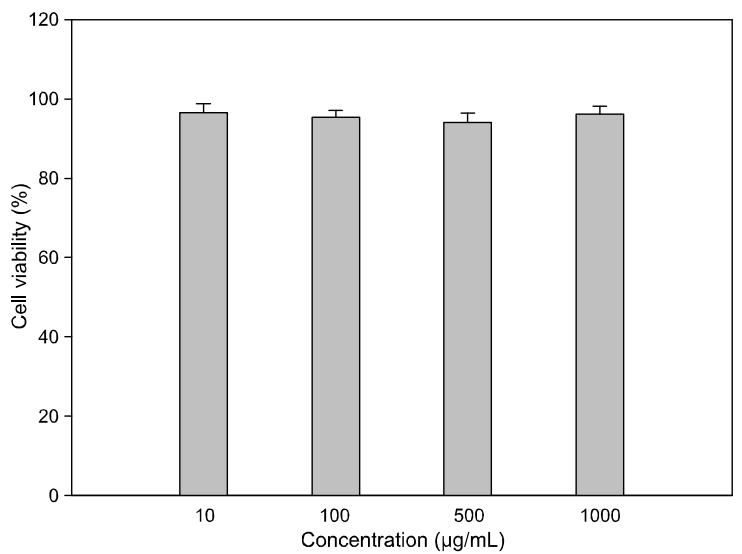

Fig. 2. Cytotoxic effects of AIGID-III on RAW264.7 macrophage cell lines. Different concentrations of samples were applied to the cells for $24 \mathrm{~h}$ and cell viability was assessed by MTT assay as described in the text. Results are means \pm standard error of three independent experiments.

Oxidative stress induced by treatment of $\mathrm{H}_{2} \mathrm{O}_{2}$ is a useful model to study oxidative injury mechanisms. Cells were exposed to $\mathrm{H}_{2} \mathrm{O}_{2}$ for $2 \mathrm{~h}$, and cell viability was determined using the MTT assay. As shown in Fig. 3, RAW264.7 cell viability increased with treatment of AIGID-III in a dose-dependent manner, and the results showed that AIGID-III treatment could enhance the viability of macrophages up to $95 \%$ at a concentration of $1,000 \mu \mathrm{g} / \mathrm{mL}$ after exposure to $\mathrm{H}_{2} \mathrm{O}_{2}$.

In the cellular system, we employed $\mathrm{H}_{2} \mathrm{O}_{2}$ to generate lipid-derived radicals. $\mathrm{H}_{2} \mathrm{O}_{2}$ rapidly penetrates into mammalian cells. The proposed mechanisms of $\mathrm{H}_{2} \mathrm{O}_{2}$-induced toxicity include the finding that cytochrome P450 catalyzes the hemolytic scission of $\mathrm{H}_{2} \mathrm{O}_{2}$ to the reactive hydroxyl radical, and as a result of catalysis, initiates peroxidation of membrane lipids (Veerman et al., 2004). These results demonstrate the ability of AIGID-III to overcome $\mathrm{H}_{2} \mathrm{O}_{2}$-induced cytotoxicity.

\section{Cellular ROS determination by DCFH-DA}

To identify preventive effects of AIGID-III against $\mathrm{H}_{2} \mathrm{O}_{2}$-induced cytotoxicity by cellular ROS, we

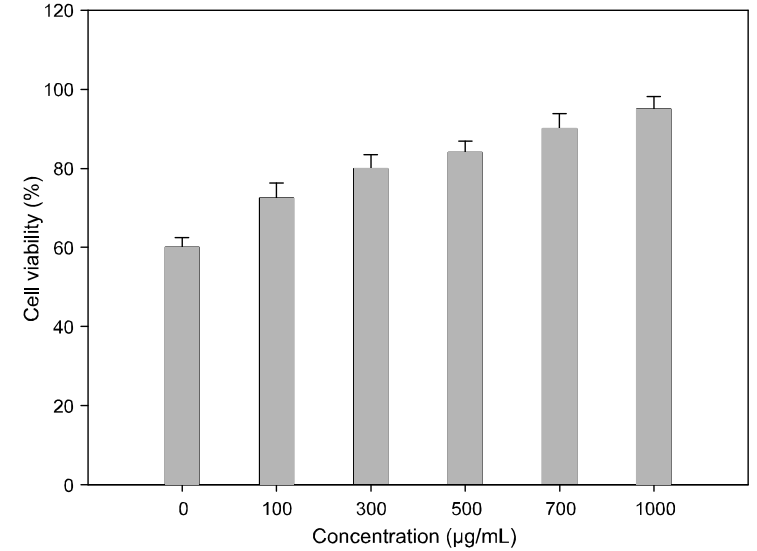

Fig. 3. Effect of AIGID-III on $\mathrm{H}_{2} \mathrm{O}_{2}$-induced cytotoxicity to RAW264.7 cells. RAW264.7 cells were cultured in DMEM medium, and cellular oxidative stress was artificially induced. Viable cells were determined by MTTassay $(n=3)$.

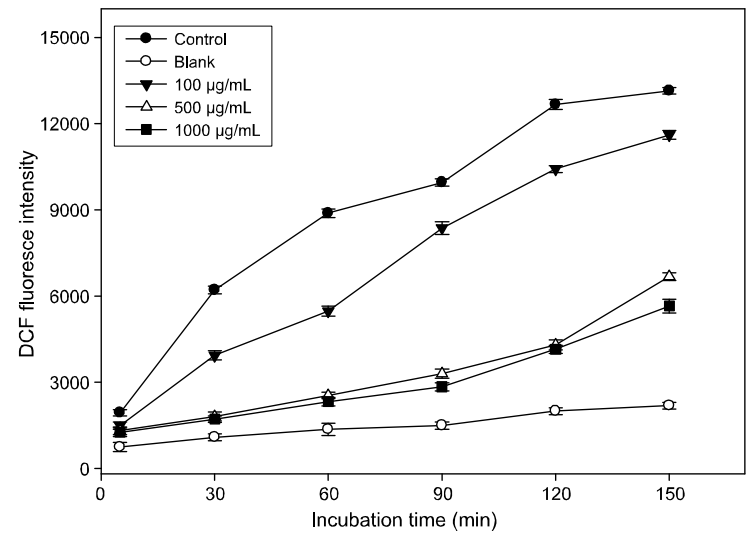

Fig. 4. Cellular radical scavenging activity of AIGIDIII at $1,000 \mu \mathrm{g} / \mathrm{mL}, 500 \mu \mathrm{g} / \mathrm{mL}$, and $100 \mu \mathrm{g} / \mathrm{mL}$. RAW264.7 cells were labeled with non-toxic fluorescence dye, DCFH-DA, and treated with different concentrations of AIGID-III. Fluorescence intensities of DCF due to oxidation of DCFH by cellular ROS (generated by $\mathrm{H}_{2} \mathrm{O}_{2}$ ) were detected time-dependently $(\lambda$ excitation $=485 \mathrm{~nm}$ and $\lambda$ emission $=528 \mathrm{~nm})$. Effects of extracts of $\mathrm{SH}$ on the scavenging of cellular ROS were compared with $\mathrm{H}_{2} \mathrm{O}_{2}$ nonstimulated blank and sample non-treated group (control) in three independent experiments.

further examined the direct effects of AIGID-III to scavenge cellular radicals; RAW264.7 cells were labeled with the fluorescent probe DCFH-DA. DCFH-DA is hydrolyzed by esterases to DCFH, which is trapped within the cells. This nonfluorescent molecule is then oxidized to DCF via the action of cellular oxidants (Robinson, 1988). As shown in Fig. 4, fluorescence emitted by DCF 
following ROS-mediated oxidation of DCFH followed a time-dependent course up to $150 \mathrm{~min}$. Pretreatment with AIGID-III decreased DCF fluorescence dose- and time-dependently. AIGID-III exerted a considerable radical scavenging effect at $100 \mu \mathrm{g} / \mathrm{mL}$ concentration after $30 \mathrm{~min}$. More clearly, at a concentration of $1,000 \mu \mathrm{g} / \mathrm{mL}$, AIGID-III could scavenge radicals significantly throughout the incubation time. These results suggest that AIGID-III can protect macrophage cells from oxidative damage by ROS. It could be developed into a potential biomolecular candidate to inhibit ROS formation of cellular damage. Furthermore, AIGID-III was shown to contain potent antioxidant activity, and inhibit radical-mediated oxidation and protect macrophage cells.

In this study, we determined that the AIGIDs of $H$. discus hannai possess high antioxidant activity and exhibit protective effects against oxidative stress in macrophage cells. In conclusion, these results suggest that AIGID-III contains bioactive compounds regarding immune and oxidative diseases, and abalone $H$. discus hannai may be a valuable invertebrate animal as a potential marine pharmaceutical resource.

\section{Acknowledgments}

This Study was supported by Fishery Technology Development Program for Fisheries, Ministry for Food, Agriculture, Forestry and Fisheries, and Wando-County Program for R\&D Services, Wandogun, Jeonnam, Republic of Korea.

\section{References}

Aruoma OI. 1994. Nutrition and health aspects of free radicals and antioxidants. Food Chem Toxicol 32, 671683.

Byun HG and Kim SK. 2001. Purification and characterization of angiotensin I converting enzyme (ACE) inhibitory peptides from Alaska pollack (Theragra chalcogramma) skin. Process Biochemi 36, 1155-1162.

Cacciuttolo MA, Trinh L, Lumpkin JA and Rao G. 1993. Hyperoxia induces DNA damage inmammalian cells. Free Radic Biol Med 14, 267-276.

Chen HM, Muramoto K and Yamauchi F. 1995. Structural analysis of antioxidative peptides from soybean bconglycinin. J Agric Food Chem 43, 574-578.

Duh PD. 1998. Antioxidant activity of burdock (Arctium lappa Linne): Its scavenging effect on free-radical and active oxygen. J Am Oil Chem Soc 75, 455-461.

Ekanayake PM et al.???, 2008. Cloning, characterization and tissue expression of disk abalone (Haliotis discus discus) catalase. Fish Shellfish Immunol 24, 267-278.

Elias RJ, Kellerby SS and Decker EA. 2008. Antioxidant activity of proteins and peptides. Crit Rev Food Sci Nutr 48, 430-441.

Erdmann K, Cheung BWY and Schroder H. 2008. The possible roles of food-derived bioactive peptides in reducing the risk of cardiovascular disease. J Nutr Biochem 19, 643-654.

Guo Q, Zhao B, Shen S, Hou J, Hu J and Xin W. 1999. ESR study on the structure-antioxidant activity relationship of tea catechins and their epimers. Biochem Biophys Acta 1427, 13-23.

Halliwell B. 1994. Free radicals, antioxidants, and human disease: curiosity, cause, or consequence? Lancet 344, 721-724.

Halliwell B and Gutteridge JMC. 1990. Role of free radicals and catalytic metal ions in human disease: an overview. Methods Enzymol 186, 1-85.

Hiramoto K, Johkoh H, Sako KI and Kikugawa K. 1993. DNA breaking activity of the carbon-centered radical generated from 2,2- azobis-(2-amidinopropane)hydrochloride (AAPH). Free Radic Res Commun 19, 323-332.

Jo HY, Jung WK and Kim SK. 2008. Purification and characterization of a novel anticoagulant peptide from marine echiuroid worm, Urechis unicinctus. Process Biochem 43,179-184.

Jung WK, Qian ZJ, Lee SH, Choi YS, Sung JN, Byun SG and Kim SW. 2007. Free radical scavenging activity of a novel antioxidative peptide isolated from in vitro gastrointestinal digests of Mytilus coruscus. J Med Food 10, 197-202.

Kapsokefalou M and Miller DD, 1991. Effects of meat and selected food components on the valence of nonheme iron during in vitro digestion. J Food Sci 56, 352-355.

Kim SY, Je JY and Kim SK. 2006. Purification and characterization of antioxidant peptide from hoki (Johnius belengerii) frame protein by gastrointestinal digestion. J Nutr Biochem 18, 31-38.

Lee SH, Lee WW, Lee JB and Jeon YJ. 2010. Evaluation of the properties of Pediastrum duplex and Dactyloccopsis fascicularis microalgae. Fish Aqua Sci $13,18-25$.

Liu et al., 2008. Production of cysteine-rich antimicrobial peptide by digestion of oyster (Crassostrea gigas) with alcalase and bromelin. Food Control 19, 231-235.

Mendis E, Rajapakse N and Kim SK. 2005. Antioxidant properties of a radicals scavenging peptide purified from enzymatically prepared fish skin gelatin hydrolysate. J Agric Food Chem 53, 581-7.

Mitsuda H, Yasumoto K and Iwami K. 1966. Antioxidative 
action of indole compounds during the autoxidation of linoleic acid. Eiyo To Shokury 19, 210-214.

Nanjo H, Adachi M, Aketa T, Mizoguchi T, Nishihara T and Terada T. 1995. The role of cysteine in the alteration of bovine liver dihydrodiol dehydrogenase 3 activity. Biochem J 310, 101-107.

Okimoto Y, Watanabe A, Niki E, Yamashita T and Noguchi N. 2000. A novel fluorescent probe diphenyl-1pyrenylphosphine to follow lipid peroxidation in cell membranes. FEBS Lett 474, 137-140.

Osawa T and Namiki M. 1985. Natural antioxidants isolated from eucalyptus leaf waxes. J Agric Food Chem 33, 777-780.

Pan Y, Zhu J, Wang H, Zhang X, Zhang Y, He C, Ji X and Li H. 2007. Antioxidant activity of ethanolic extract of Cortex fraxini and use in peanut oil. Food Chem 103, 913-918.

Qian ZJ, Jung WK, Byun HG and Kim SK. 2008. Protective effect of an antioxidative peptide purified from gastrointestinal digests of oyster, Crassostrea gigas against free radical induced DNA damage. Bioresource Technol 99, 3365-3371.

Rackov L, Oblozinsky M, Kostalova D, Kettmann V and Bezakova L. 2007. Free radical scavenging activity and lipoxygenase inhibition of Mahonia aquifolium extract and isoquinoline alkaloids. J Inflamm, 4-15.

Roberts PR, Burney JD, Black KE and Zaloga GP. 1999. Effect of chain length on absorption of biologically active peptides from the gastrointestinal tract. $\mathrm{J}$ Gastroenterol 60, 332-337.

Robinson JP. 1988. Measurement of intracellular fluorescence of human monocytes relative to oxidative metabolism. J Leukocyte Biol 43, 304-310.

Rosen GM and Rauckman EJ. 1984. Spin trapping of superoxide and hydroxyl radicals. Methods Enzymol 105, 198-209.

Sun L, Zhu B, Li D, Wang L, Dong X, Murata Y, Xing R and Dong Y. 2010. Purification and bioactivity of a sulphated polysaccharide conjugate from viscera of abalone Haliotis discus hannai Ino. Food Agr Immunol 21, 15-26.

Veerman ECI, Nazmi K, Van’t Hof W, Bolscher JGM, Den Hertog A and Nieuw Amerongen AV. 2004. Reactive oxygen species play no role in the candidacidal activity of the salivary antimicrobial peptide histatin 5 . Biochem J 381, 447-452.

Vermeirssen V, Bent AVD, Camp JV, Amerongen AV and Verstraete W. 2004. A quantitative in silico analysis calculates the angiotensin I converting enzyme (ACE) inhibitory activity in pea and whey protein digests. Biochimie 86, 231-239.

Wan Q, Whang I and Lee J. 2008. Molecular characterization of mu class glutathione-Stransferase from disk abalone (Haliotis discus discus), a potential biomarker of endocrine-disrupting chemicals. Comp Biochem Physiol B 150, 187-199.

Zhu BW, Wang LS, Zhou DY, Li DM, Sun LM, Yang JF, Wu HT, Zhou XQ and Mikiro T. 2008. Antioxidant activity of sulphated polysaccharide conjugates from abalone (Haliotis discus hannai Ino). Eur Food Res Technol 227, 1663-1668.

(Received 25 June 2010; Revised 10 August 2010; Accepted 10 September 2010) 